\title{
Desarrollo y políticas regionales
}

A lo largo de 34 años de publicación regular e ininterrumpida, EURE alcanza con la presente edición su número 90, dando continuidad a un proceso que ha estado guiado por el objetivo de promover en el ámbito latinoamericano el análisis y la discusión sobre los principales temas relativos al desarrollo urbano, regional y local. En el cumplimiento de esta tarea, EURE ha logrado revisar, desde una perspectiva multidisplinaria, los más diversos aspectos y dimensiones de esta materia, para lo cual ha concitado la colaboración de los más destacados especialistas en el tema, tanto latinoamericanos como de otros países y continentes.

En este proceso, en el que se ha constituido en la más antigua revista latinoamericana urbano-regional, el flujo de artículos recibidos de parte de un número creciente de colaboradores ha obligado a los responsables de su publicación a realizar un mayor esfuerzo en términos de acuciosidad y rigurosidad, a fin de preservar y mejorar la calidad y representatividad del material que, con la valiosa e imprescindible colaboración de su Comité Asesor, es seleccionado y publicado en cada número.

$\mathrm{Al}$ avanzar en esta dirección, una de las preocupaciones centrales de EURE ha sido tratar de identificar e incorporar los nuevos problemas y temas generados en cada uno de los momentos del proceso modernizador vivido a lo largo de estos 34 años, promoviendo su análisis y, en especial, la discusión en torno a sus implicancias. En esta tarea, ha puesto especial atención en el tratamiento de los temas que han concitado en mayor grado el interés de los investigadores que han escogido sus páginas para la publicación de sus trabajos. Ahora, en esta nueva fase modernizadora que están enfrentando nuestros países bajo los efectos de la reestructuración productiva y la globalización, otros temas y problemas se han ido priorizando en la agenda de la gestión urbana, regional, local y ambiental.

En este escenario, buscando focalizar la atención en los temas de mayor relevancia de dicha agenda,
EURE ha decidido establecer un tema central para cada uno de sus números, el que será cubierto por varios artículos seleccionados entre el material recibido regularmente, al cual, en algunos casos, se agregarán trabajos especialmente invitados de los autores de mayor relevancia en esta área del conocimiento. En la medida que los diversos artículos que son sometidos a la consideración de nuestra revista expresan las preocupaciones dominantes de cada momento entre los estudiosos y los planificadores urbanos y regionales, creemos que por esta vía iremos reflejando los puntos más destacados del debate actual en este campo.

Dando inicio a esta política, EURE ha decidido focalizar su atención en esta oportunidad a un conjunto de temas y problemas sobre desarrollo y políticas regionales, que han estado emergiendo y posicionándose asociados a las transformaciones derivadas de los avances de la globalización y la informacionalización en la mayoría de los países latinoamericanos. Con este propósito, hemos seleccionado un conjunto de contribuciones concebidas desde esta perspectiva, recibidos durante los últimos meses y que, en su conjunto, suministran un comprensivo panorama sobre estas nuevas preocupaciones.

En la materialización de esta iniciativa, este número comienza con un trabajo de Edgar Moncayo, motivado por la comprobación de que la globalización con sus efectos diferenciadores por países, regiones subnacionales y grupos sociales, ha reactivado el debate sobre la hipótesis de convergencia, que está en la base de la teoría neoclásica del crecimiento. A partir de allí, y luego de una exhaustiva revisión de la evidencia empírica sobre convergencia/divergencia en los niveles de ingreso per cápita, tanto entre países como entre regiones subnacionales, el autor concluye que se estaría en presencia de una evolución que parecería darle la razón a las teorías de crecimiento endógeno y de la nueva geografía económica, en el sentido de que la actividad productiva tiende a seguirse aglomeran- 
do allí donde ya está concentrada, con una lógica de causación circular acumulativa, tanto a escala de países como de regiones.

A continuación Sergio Boisier, partiendo del reconocimiento de la ambigüedad que acompaña al concepto de descentralización en América Latina, muchas veces confundido con el de desconcentración -o aun con el de deslocalización-, revisa desde una perspectiva predominantemente conceptual diversos aspectos vinculados a este concepto. En este recorrido, destaca la importancia de entender a la descentralización como una profunda modificación del "contrato social" entre el Estado y la sociedad civil, planteando la necesidad de estructurar un nuevo cuerpo cognitivo para usar con eficacia los espacios abiertos por el proceso descentralizador, al tiempo que previene acerca de la necesidad de modernizar la gestión social del territorio sin volver a caer en el iluminismo racionalista de los ' 60 .

En el artículo siguiente, Valentina Viego aborda el tema de las relaciones entre empresarialidad e instituciones, consideradas como dos nuevas perspectivas del análisis regional contemporáneo. Para ello revisa los principales avances en el análisis de la empresarialidad, en relación al reciente enfoque de la economía institucional y su integración a la teoría general del desarrollo económico, y muestra la centralidad que estos temas han adquirido en los enfoques contemporáneos sobre desarrollo territorial.

Claudia Tomadoni, por su parte, encara la revisión de algunas cuestiones conceptuales y metodológicas en torno a las relaciones entre producción flexible, territorio y territorialidad; para documentar su análisis, examina las lógicas y estrategias de una empresa transnacional automotriz sobre el territorio, tomando como caso de estudio el de la empresa Daimler-Chrysler localizada en la Región Metropolitana Córdoba en la República Argentina. A partir del análisis de esta experiencia, la autora fundamenta la propuesta de que la implementación de la producción flexible genera territorios "glocaldependientes" en los ámbitos periféricos.

A su vez, el trabajo de Leandro Silva y Rodrigo Simões expone los resultados de una investigación preliminar para la economía brasileña, en la que utilizando recursos de análisis multivariado sobre localización de las actividades científicas e industriales, estudia las relaciones de interactividad entre la industria y la creación de oportunidades tecnológicas a nivel microrregional. Con esta base, el trabajo analiza las cuestiones relativas a oportunidades tecnológicas y producción, vinculadas al tema de los clusters productivos, y explora la posibilidad de suministrar elementos útiles para el planteo de estrategias de desarrollo económico regional.

Finalmente, Miguel Ángel Barreto y José Raúl Zavala analizan el modelo de de inversión urbana pública implementada en el nordeste argentino a partir de las reformas estructurales de la década de los ' 90 , en las que incidieron los fundamentos teóricos sustentados por los organismos financieros internacionales para los países de menor desarrollo al momento de materializar sus programas de créditos. El trabajo argumenta que estas políticas no sólo han contribuido al endeudamiento externo de estos países, sino que han profundizado la separación entre planeamiento y demandas sociales, y reflexiona sobre la necesidad de alcanzar una articulación horizontal en la gestión urbana como verdadero instrumento del desarrollo local.

Con estos trabajos, EURE pretende suministrar un amplio abanico de elementos de juicio orientados a enriquecer la discusión actual sobre los problemas y las políticas relativos al desarrollo regional y local en América Latina, cuando los impactos de una nueva fase de modernización capitalista impulsada por la globalización e informacionalización está redefiniendo la agenda respectiva y priorizando nuevos problemas y desafíos. 